\title{
Design Remote Learning to Help Students Feel Connected
}

\author{
Rob Mitchell (Colorado State University)
}

KEYWORDS: Information Technology, Teaching

Methods.

Online learning is unsettling new territory for professors and students, with many professors using it for the first time. As all of us switch to new ways of teaching, l'd like to share one of my surprising discoveries about switching from in-class sessions to online teaching: Done right, online teaching can help students actually engage more with their professors and with one another.

That may sound surprising, but it has been my experience. In today's constrained environment, when social distancing can so easily lead to feelings of isolation, we can harness online teaching technology to find new ways to engage students and bring in others who can help make the learning experience richer. I've have noticed that the more introverted students who are shy about speaking up in class end up being more "vocal" in our synchronous and asynchronous chat sessions if given an avenue for sharing their perspectives online. In this setting, they have the time to think out their input instead of being put on the spot.

Here are some things to consider.

\section{Allow for Different Kinds of Access}

Lots of software tools with useful features are available to help you launch your online classroom. This article (https://familybusiness.org/content/technology-tools-forworking-or-teaching-remotely) lists many of them and what they can do; many others exist. But be thoughtful of students who are going through tough times and who may not have the technology to use all the bells and whistles available to others. Allow for dial-up access. Both Zoom and Microsoft Teams can allow for this functionality.

\section{Be Aware of Students' Circumstances}

Food insecurity and health problems were issues for some students even before the pandemic. It may be worse now if they are living on their own or as part of a household that is struggling. For that reason, make it easier for them to access material and assignments and supporting material on a flexible time frame and in smaller doses.

\section{Mix Synchronous and Asynchronous}

Synchronous learning means bringing everybody together at the same time. It helps reinforce connection by recreating the feeling of being in the same room at the same time. It provides students a voice that can feel like it has been lost. Strive to include some of this in your plan, realizing that some students in far-off time zones will have some limits. Asynchronous learning allows students to access material, do research, and talk with you and one another on their own schedule. To help everyone get ready for the class on their own time, use software such as YellowDig. I have used YellowDig as a replacement tool for quizzes to ensure engagement with the material. With YellowDig, students are given points according to their participation in a discussion forum (e.g., the professor can set up the number of points students can get from starting a post, responding to posts, having others respond to their posts, etc.). By recording the in-class discussions, the students who are not able to join the session can engage with the material and those who were in class can also review material. Microsoft Teams, Zoom, Big Blue Button and other platforms all allow you to do this. After the class, these same tools can enable the students to engage in written discussions of questions that are provided in the synchronous portion. They can then engage this material on their own time. Students are also able to introduce their own related material for discussion in these forums.

\section{Be Adaptable}

Engaging and rich content (e.g., case studies, experiential content, live cases based on current events, interactive lectures, etc.) give professors and students many ways to dive into the material in their own way and on their own time. Choose cases and materials that will
Copyright $@ 2020$ The Authors. Entrepreneur \& Innovation Exchange is published at EIX.org. This is an open access article under the terms of the Creative Commons Attribution-NoDerivs License, which permits use and distribution in any medium, provided the original work is properly cited and no modifications or adaptations are made. View EIX.org Authorship Terms at https://eix.org/terms
FamilyBusiness 
provide many possible avenues for students to grasp important concepts. Some professors are using "choose your own adventure" formats to help students explore possible outcomes for the case study. In such cases, the students are not working to find the "right" answer, but rather must come up with their own answers that they must justify. There are published cases that adopt this approach (for example Ivey Cases 9B12M072 (https://www.iveycases.com/ProductView.aspx?id=554 06) and 9B14M140 (https://www.iveycases.com/ProductView.aspx?id=692 48) ), but such cases can also be created by creating brief vignettes of challenges faced by entrepreneurs and then asking the students to describe what they would do, why they would do it and (importantly) specifically how they would do this. Such an approach focuses on students practicing the process of making decisions in the face of uncertainty.

\section{Get Help}

For professors, it can be a challenge to manage a switch to online teaching in the face of stay-at-home orders and uncertainty regarding their own health and that of friends and loved ones. One way to address this is to enlist the support of graduate students, teaching assistants or even students in class to help manage individual questions from students during a class and resolve technical issues. This can free up the professor to interact with the students more naturally during the real-time part of the course, with a minimum of disruptions. And because the pandemic has sidelined many talented business owners and professionals, consider asking those who you know are available if they can serve as advisors or mentors to students, or talk to your class about their experiences.

This disruption is having a significant impact in the lives of so many. The notion of social distancing needs to be countered with social connectedness that can come through online learning and engagement. When done with purpose and compassion, the abruptness of online learning may be able to pave the way for lasting connections long after the pandemic is over. 